\title{
Epithelial and Endothelial Expressions of ACE2: SARS-CoV-2 Entry Routes
}

\author{
Ceren Guney and Fatma Akar
}

Department of Pharmacology, Faculty of Pharmacy, Gazi University, Ankara, Turkey

Corresponding author: Fatma Akar, Gazi University, Faculty of Pharmacy, Department of Pharmacology, 06330, Etiler, Ankara, Turkey; TEL: (+90)-312 2023127; Fax: (+90)-312 2235018; e-mail: fakar@gazi.edu.tr

Received, October 17, 2020; Revised, February 9, 2021; Accepted, February 19, 2021; Published, February 23, 2021

\begin{abstract}
Angiotensin converting enzyme 2 (ACE2) is a main receptor for SARS-CoV-2 entry to the host cell. ACE2 is one of the key enzymes in renin-angiotensin system and plays a vital role in the maintenance of cardiovascular function. ACE/ACE2 balance is critical in the regulation of blood pressure, electrolyte homeostasis, vascular and cardiac remodeling and inflammation. ACE2 was shown to be abundantly present in human epithelial cells of the lung and enterocytes of the small intestine as well as in endothelial cells of the arterial and venous vessels. ACE2 and TMPRSS2 are colocalized on the cell surface and produced a critical step host cell entry of SARS-CoV-2. TMPRSS2-cleaved ACE2 permits SARS-CoV-2 host cell entry however, ADAM17-cleaved ACE2 produces protective effects in several organs. Differently, basigin (CD147) was suggested as a putative alternate receptor for SARS-CoV-2 entry into endothelial cells. The intestinal ACE2 receptor is associated with the neutral amino acid transporter B0AT1 and ACE2 is necessary for the expression of this transporter on the luminal surface of intestinal epithelial cells. There is a good association between the localization of SARS-CoV-2 binding receptor ACE2 and the disease target organs in respiratory, cardiovascular and gastrointestinal systems. Decreased expression of ACE2, being a receptor for coronavirus, would prevent cellular entry of the virus thereby reducing progression of the infection. However, increased ACE2 expression produces beneficial health effects. Further studies are needed to clarify this conflicting situation. Currently, it is recommended to continue the therapy with ACE2-increasing drugs in patients with COVID-19.
\end{abstract}

\section{INTRODUCTION}

Coronaviruses $(\mathrm{CoV})$ are a large family of viruses that cause a variety of diseases representing common colds such as the Middle East Respiratory Syndrome (MERS) and Severe Acute Respiratory Syndrome (SARS). A new coronavirus, which is first identified in humans in December 2019 in China, was named as SARS-CoV-2 due to its similarity to the SARS-CoV. SARS-CoV-2 causes Coronavirus disease 2019 which is abbreviated as COVID-19. Common symptoms of the disease are cough, fever, shortness of breath, fatigue, diarrhea and loss of smell and taste $(1,2)$. In more serious cases, pneumonia, severe acute respiratory infection, multiple organ failure, and even death may occur. Human coronaviruses mainly infect the respiratory tract by binding to the receptor in airway epithelial cells.

Coronaviruses are in the Coronaviridae family and the Orthocoronavirinae subfamily which is classified into four genera: Alpha, Beta, Gamma and Deltacoronavirus genera (5). SARS$\mathrm{CoV}-2$ is a family of the Sarbecovirus subspecies in the genus of Betacoronavirus, like SARS-CoV and MERS-CoV (6). Coronaviruses are large, roughly spherical, single-chain, enveloped RNA viruses. The viral envelope consists of at least three structural proteins such as the membrane protein $(\mathrm{M})$, the envelope protein $(\mathrm{E})$ and the spike protein (S). Coronavirus $\mathrm{S}$ protein mediates the virus entry into the host cells, whereas $\mathrm{M}$ and $\mathrm{E}$ proteins are functional to produce of viral structure. The $\mathrm{S}$ protein of the virus is composed of S1 and S2 subunits. The S1 unit has the receptor binding domain, which is the host cell surface for viral attachment, but the S2 unit has protease activity and thus causing the fusion of the host cell membrane, allowing viral genomes to enter the host cell. The binding of spike proteins to the receptor is the initial and critical steps in the coronavirus infection cycle $(7,8)$. Angiotensin converting enzyme 2 (ACE2) is a main receptor for SARS-CoV-2 to enter the host cell. New SARSCoV-2 binding affinity to human ACE2 is stronger (10-20 times more) than old SARS-CoV (9).

\section{Biological importance of ACE and ACE2}

ACE2, a homolog of angiotensin converting enzyme (ACE), is an important member of reninangiotensin-aldosterone system (10). 
ABBREVIATIONS: ACE, Angiotensin converting enzyme; ACE2, Angiotensin converting enzyme 2; ACEi, ACE inhibitors; ADAM17, Disintegrin and metalloprotease 17; ARB, angiotensin receptor blockers; AT1R, angiotensin II type 1 receptors; B0AT1, Sodiumdependent neutral amino acid transporter; CoV, Coronaviruses; COVID-19, Coronavirus disease 2019; SARS-CoV, Severe Acute Respiratory Syndrome coronavirus; SARS-CoV-2, Severe Acute Respiratory Syndrome coronavirus 2; TMPRSS2, Transmembrane serine protease 2 .

Angiotensinogen produced by the liver is converted to angiotensin I via renin enzyme derived from the kidney. In the second step, ACE catalyses the conversion of angiotensin I to angiotensin II. Angiotensin II, acting on angiotensin II type 1 receptors (AT1R) exerts wellknown cardiovascular effects including vasoconstriction and stimulation of aldosterone synthesis. Moreover, angiotensin II leads to structural remodeling on cardiac and vascular tissues as well as activating the inflammatory pathway. In the meantime, ACE2 converts angiotensin II to angiotensin 1-7 and also angiotensin I to angiotensin 1-9, which in turn cleaves to angiotensin 1-7 via classical ACE. Angiotensin 1-7 shows vasodilatory, antiinflammatory and antifibrotic effects through the Mas receptor. However, angiotensin 1-9 activates natriuresis and nitric oxide production, thus reducing blood pressure. Additionally, this peptide has antiinflammatory and antihypertrophic effects $(11,12)$. These angiotensin peptides were shown to counteract the harmful effect of classical renin-angiotensin system signifying a potential therapeutic target (Figure 1). Therefore, ACE/ACE2 balance was suggested to play a critical role in the regulation of blood pressure, electrolyte homeostasis, vascular and cardiac remodeling as well as inflammation. This balance can be deteriorated by several diseases including systemic and pulmonary hypertension, coronary heart disease, diabetes, obesity and aging (11, 1317). Several dietary factors, especially in the situation of excess intake of sodium, fat and fructose are detected to shift the ACE/ACE2 balance towards the unfavorable balance (18-20). Furthermore, some studies in animal models and humans indicated that selective blockade of either ACE or angiotensin receptor increased cardiac and intestinal ACE2 gene expression thus improving ACE/ACE2 ratio (21-23). Estrogen, exercise and resveratrol were shown to promote the balance from $\mathrm{ACE}$ to $\mathrm{ACE} 2$ representing beneficial factors in the maintenance of a healthy condition $(15,24$ 26). Figure 2 shows the modification of the balance between ACE and ACE2 by several factors.

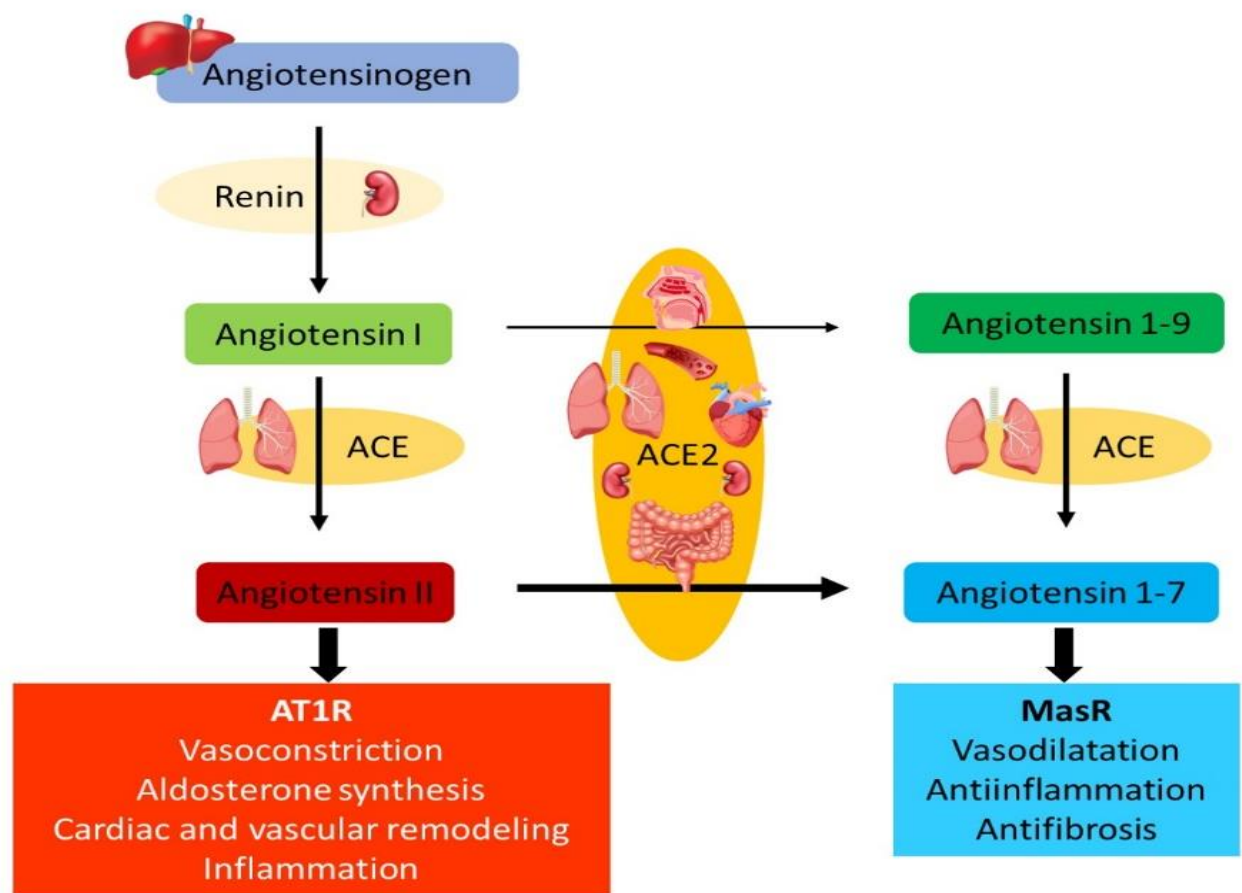

Figure 1. Diagram of the renin-angiotensin system. The functions of ACE and ACE2. ACE: angiotensin converting enzyme; ACE2: angiotensin converting enzyme 2; AT1R: angiotensin II type 1 receptor; MasR is a receptor of angiotensin $1-7$. 


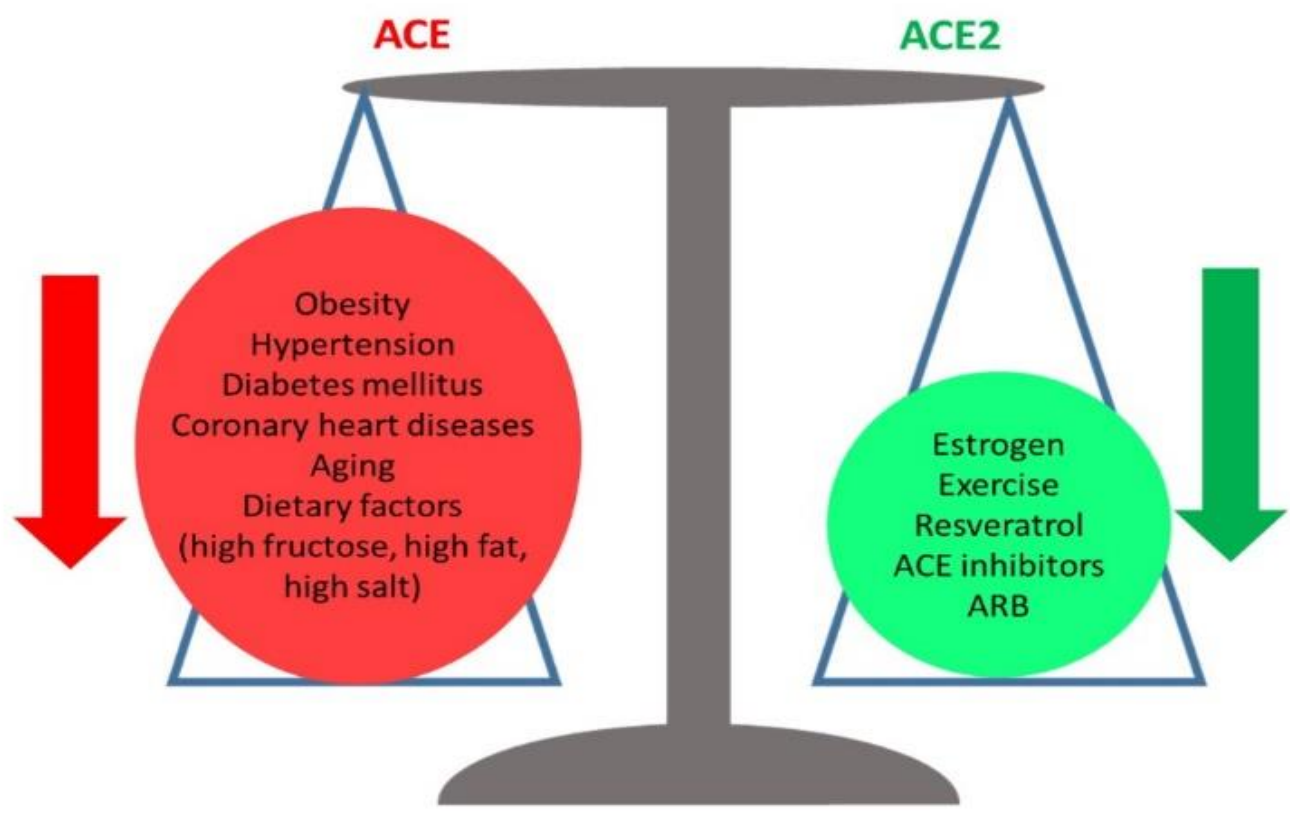

Figure 2. The modification of the balance between ACE and ACE2 by several pathological, physiological, dietary and lifestyle factors and the medications. ACE inhibitors: angiotensin converting enzyme inhibitors; ARB: angiotensin II receptor blockers.

\section{The role of ACE2 in the SARS-CoV-2 entry}

ACE2 protein was found in two forms, namely cell membrane-bound and circulating soluble forms. Soluble ACE2 is produced by metalloprotease ADAM17 and released into the blood thus preventing viral invasion into the host cell and its spread (27). Circulating ACE2 also binds to the virus and this soluble form may act as a competitive interceptor of SARS-CoV-2 by preventing the binding of the virus to the membrane-bound ACE2 (28). Soluble ACE2 has been proposed to provide a protective effect in several organs such as in the lung and kidney (29-31). TMPRSS2, which is a transmembrane protease, was present to compete with ADAM17 for ACE2 shedding, but only cleavage by TMPRSS2 results in increased virus entry (31). ACE2 and TMPRSS2 were shown to colocalize on the cell surface and produce a critical step in host cell entry of SARS-CoV-2 (8). Interestingly, activation of AT1R by angiotensin II was shown to increase the expression of ADAM17, thus enhancing soluble ACE2 levels and slowing virus entry (32). On the contrary, it has been shown that elevated angiotensin II levels decrease ACE2 expression and activity by activation of lysosomal degradation through an AT1R-dependent internalization mechanism (33). ACE2 was known as an essential receptor in the virus invasion however, basigin (CD147) has been suggested as a putative alternate receptor for SARS-CoV-2 entry into endothelial cells. Basigin, a member of the immunoglobulin superfamily, was identified as a novel receptor of the spike protein which facilitates the viral invasion of the host cell in immunoprecipitation study (34). The analyses of data from the genotype-tissue expression project showed that basigin and PPIB (Peptidylprolyl Isomerase B) were highly expressed in vessels and endothelial cells compared to the lung and airway epithelial cells (35). Previously, basigin was shown to be associated with the SARS viruses and to play a functional role in invasion of host cells by SARS$\mathrm{CoV}$ (36). These findings may produce some evidence for a basigin pathway that is utilized by SARS-CoV-2 thus providing an explanation for COVID-19 dependent cardiovascular complications because basigin was previously shown to promote cardiac hypertrophy, endothelial dysfunction, platelet activation and inflammation $(37,38)$. Given the above results, it is reasonable to propose that ACE2 and basigin receptors are the binding sites of viral entry into the human cells.

\section{Epithelial and endothelial expressions of ACE2 in the viral entry routes}

ACE2 was shown to be abundantly present in human epithelial cells of lung and enterocytes of the small intestine as well as in the arterial and venous endothelial cells. The epithelial and endothelial expressions of the ACE2 provide a 
basic knowledge on the entry routes of the SARS$\mathrm{CoV}$ and its replication as well as understanding the pathogenesis of the disease (39). Very recently, immunofluorescence analysis showed that ACE2 is abundantly expressed in surface epithelial cells from oral mucosa and exfoliated epithelial cells in saliva thus ACE2 measurement in the sample of saliva could be valuable in diagnosis of COVID-19 infection (40). Immunofluorescence staining and single cell gene atlas studies demonstrated that ACE2 is mainly expressed in alveolar epithelial type II cells and apical airway epithelial cells in humans $(41,42)$. Analysis of human, non-human primate and mouse single-cell RNA-sequencing datasets showed that ACE2 and TMPRSS2 are coexpressed in lung pneumocytes, ileal absorptive enterocytes and nasal goblet secretory cells. Also, ACE2 was reported to be a human interferon- stimulated gene and the specific interferon-driven upregulation of ACE2 was a tissue-protective mediator (43). On the other hand, existence of the virus was determined in tear and conjunctival swab specimens in patients with COVID-19 (44). Consistently, immunofluorescence and immunohistochemistry studies demonstrated that ACE2 and TMPRSS2 are coexpressed in corneal epithelium and endothelium as well as conjunctival epithelium, revealing possible ocular reservoir and transmission of the virus $(45,46)$. These experimental findings with the epithelial cells from the respiratory tract could be important in understanding the entry site of the virus. Given all together, Figure 3 shows representative entry of SARS-CoV-2 into epithelial cells of the respiratory tract.

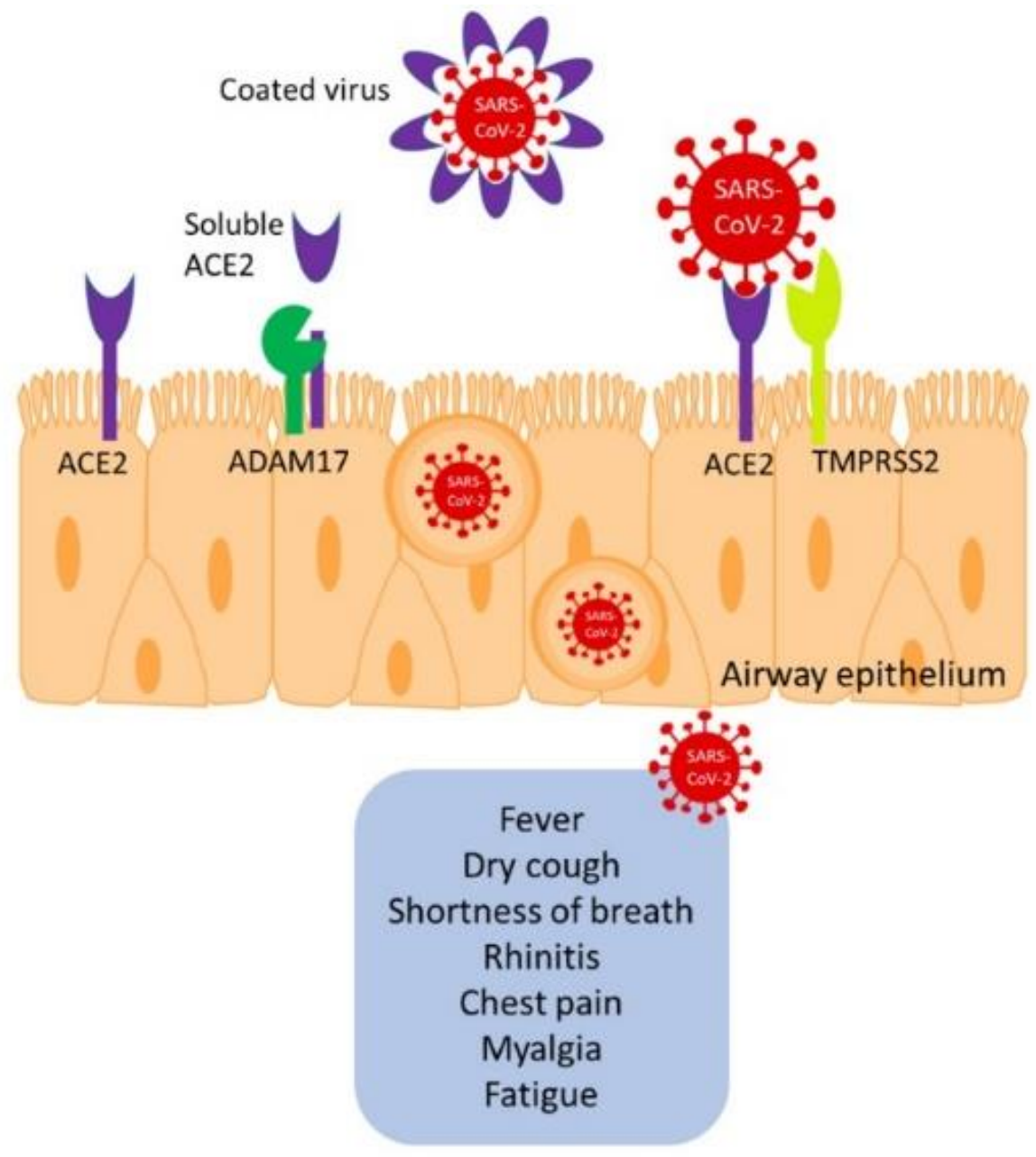

Figure 3. Cellular entry of SARS-CoV-2 into the respiratory system. ACE2 and TMPRSS2 are colocalized on the cell surface and produced a critical step host cell entry of SARS-CoV-2. ADAM17 regulates proteolytic shedding of ACE2 (soluble ACE2). Soluble ACE2 prevents the entry of the virus into airway epithelium by producing a circulatory form of the pathogen (coated virus). TMPRSS2-cleaved ACE2 permits SARS-CoV-2 host cell entry however, ADAM17-cleaved ACE2 produces protective effects in several organs. TMPRSS2: Transmembrane Serine Protease 2; ADAM17: Disintegrin and Metalloprotease 17. 
Moreover, ACE2 was found to be highly expressed on the luminal surface of intestinal epithelial cells (39). ACE2 deficiency in a murine model results in increased susceptibility to intestinal inflammation. In the same study, it was shown that intestinal ACE2 receptor has a function for viral entry as well as amino acid transport (47). ACE2 was reported to be associated with the neutral amino acid transporter B0AT1 and ACE2 is necessary for the expression of this transporter on the luminal surface of intestinal epithelial cells. Intestinal amino acid absorption is prevented due to the virus invading ACE2 $(47,48)$. This blockage may explain the gastrointestinal complications of COVID-19 such as enteritis and diarrhea ranging from $2 \%$ to $50 \%$ of cases (49). Confocal and electron microscopy studies demonstrated that human enterocytes were infected by SARS-CoV-2 revealing that intestinal epithelium could be a site of the virus replication (50). Furthermore, ACE2 and TMPRSS2 were reported to coexpress in absorptive enterocytes from the ileum and colon as well as in lung alveolar type 2 cells (51). These findings provide the evidence for SARS-CoV-2induced gastrointestinal and respiratory symptoms also for a possible fecal-oral transmission of virus. In a study conducted to investigate whether SARS$\mathrm{CoV}-2$ replicates in the human intestine, the virus was detected to cause infection in ACE2 mature enterocytes in human intestine. TMPRSS2 was shown to facilitate spike fusogenic activity and promote virus entry into host cells. Additionally, it was found that human colonic fluid inactivates the virus. However, an intestinal leak was proposed to allow the virus to disseminate to other systemic organs (52). All these revealed that the intestine might be an entry site for SARS-CoV-2 (Figure 4). This putative entry route may be crucial in understanding the initiation of the outbreak by eating food from the Wuhan market.

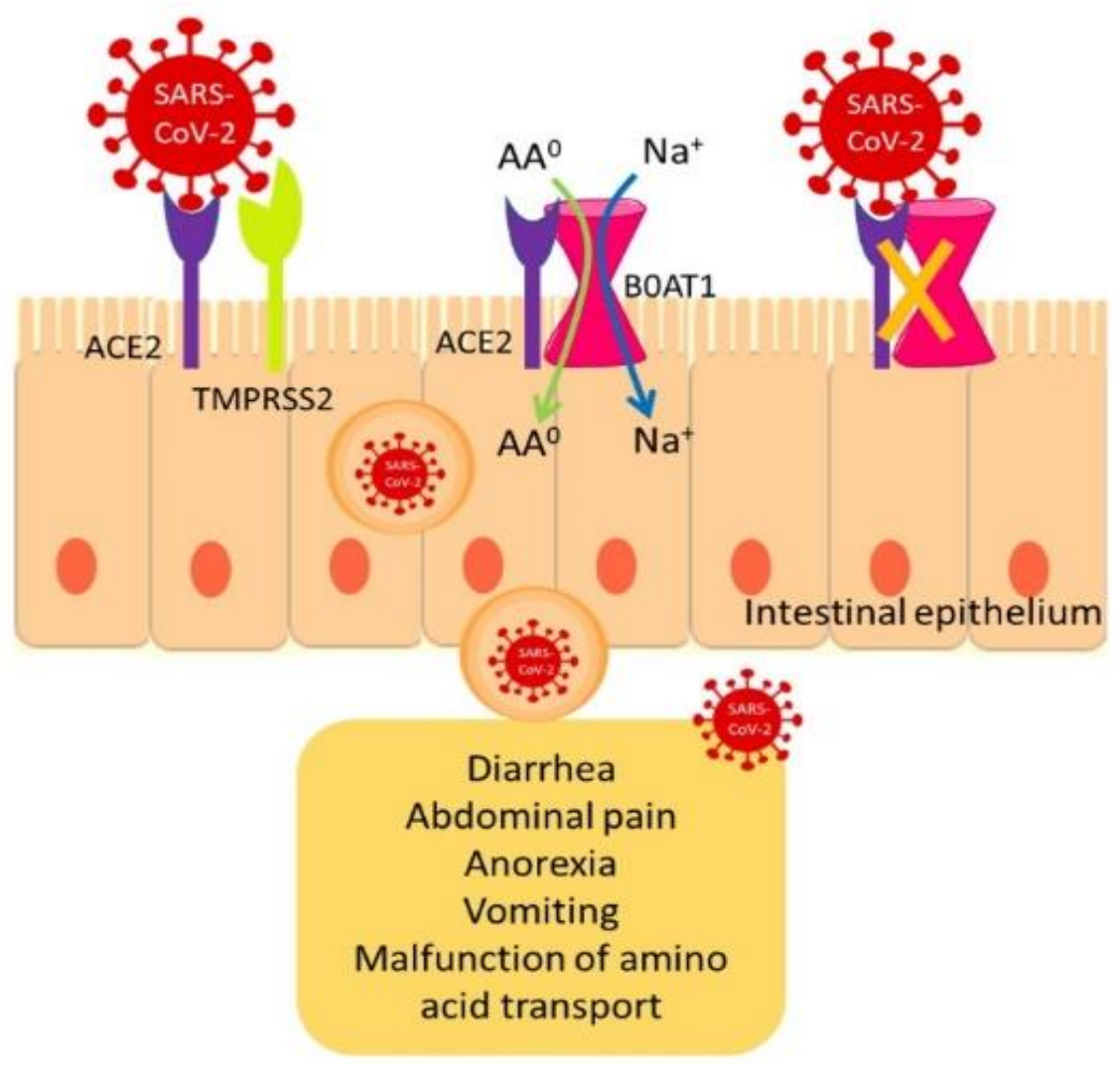

Figure 4. Intestinal ACE2 receptor mediates the viral entry and neutral amino acid transport. AA ${ }^{0}$ : Neutral amino acid; B0AT1: Sodium-dependent neutral amino acid transporter.

As mentioned above, ACE2 is one of the key enzymes in renin-angiotensin system and plays a vital role in maintenaning of the cardiovascular function (11). In this context, immunohisto- chemistry studies showed that ACE2 was greatly expressed in coronary and intrarenal endothelial cells compared to cardiomyocytes revealing a tissue-specific enzyme (10). ACE2 gene and 
protein expressions were shown to diminish in hearts from hypertensive and salt loading rats. In the same study, genetic inactivation of ACE2 using homologous recombination was determined to cause the elevation in angiotensin II levels in mice (53). Also, the existence of ACE2 mRNA and protein was determined in endothelial cells of human carotid arteries (54). The vascular complications seen in COVID-19 might be related to the endothelial invasion of the virus because there is some clinical evidence for this assumption. In a study, COVID-19 patients were determined to have elevated von Willebrand factor activity and antigen level signifying endothelial stimulation and damage (55). In the other study, ischemic changes with organ dysfunction and disseminated intravascular coagulation were observed in patients with COVID-19 (56). In post-mortem analysis using electron microscopy of COVID-19 patients, it was determined there was viral inclusion structures in endothelial cells. Furthermore, in histological studies, accumulation of endotheliumderived inflammatory cells and apoptotic bodies were established in the heart, small intestine and lung. These findings proposed that COVID-19induced endotheliitis in various organs may result in endothelial dysfunction and platelet activation subsequently induction of a coagulation cascade (57). All these studies proposed that the virus may directly infect endothelial cells and cause widespread vascular inflammatory diseases. Figure 5 summarizes SARS-CoV-2 entry mechanism into endothelial cell and subsequent pathologic conditions.

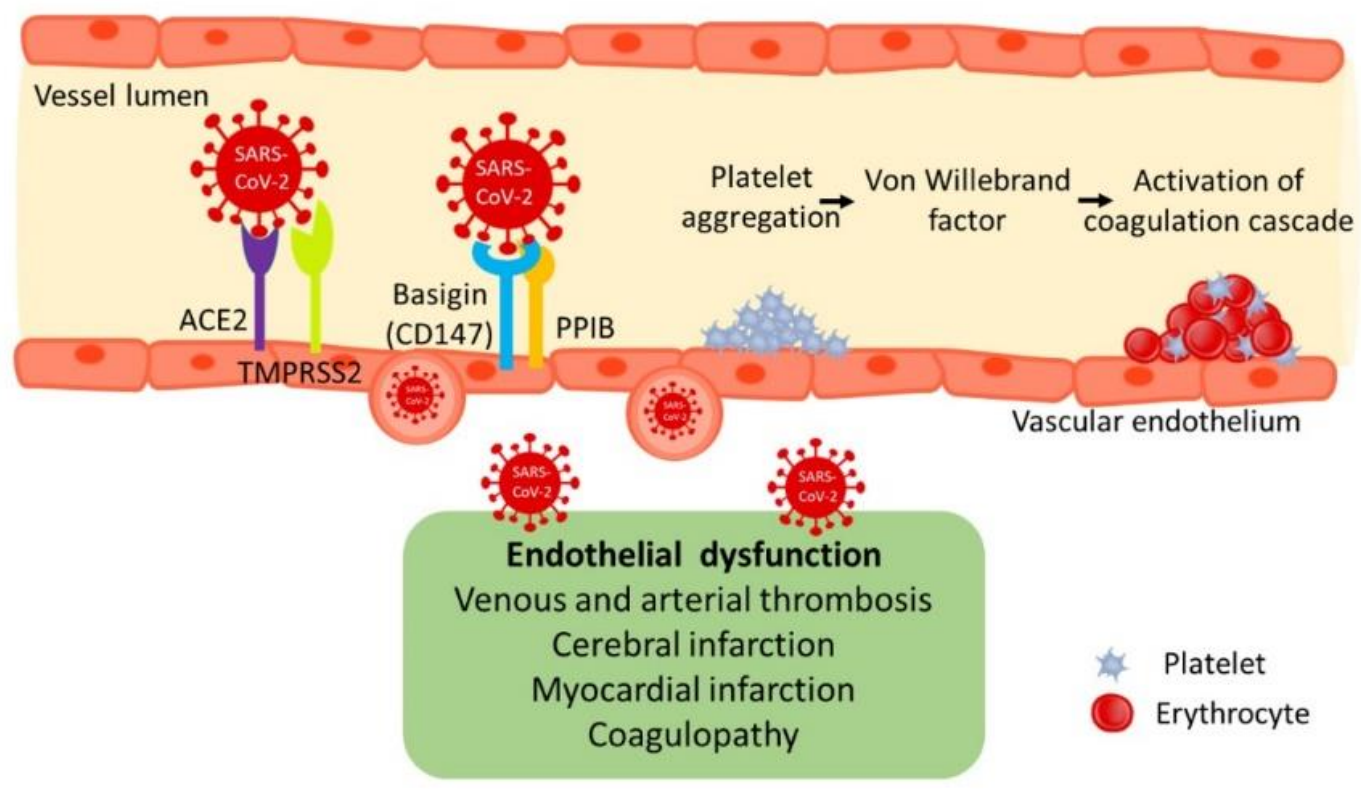

Figure 5. SARS-CoV-2 entry into endothelial cells. ACE2 and TMPRSS2 mediate the main cell entry of the virus. Basigin is also suggested as a putative alternate receptor for SARS-CoV-2 entry into endothelial cell. PPIB is a natural ligand for basigin to facilitate integration of pathogen. PPIB: Peptidylprolyl Isomerase B.

\section{The clinical perspective on ACE/ACE2 and COVID-19}

Coronary heart disease, diabetes, hypertension and obesity, as well as being older aged and of male gender, are reported to worsen the pathogenesis of COVID-19 and to increase the morbidity rate (58). ACE2 enzyme has an important function in the cardiovascular system producing a negative regulatory effect of classical ACE, because reduced expression of ACE2 was reported to be associated with many cardiovascular diseases (59). The imbalance between ACE and ACE2 may cause the worsening of endothelial dysfunction in COVID-19 patients with diabetes and hypertension (60). In this line, it was very recently reported that plasma angiotensin II levels are increased in COVID-19 patients (61). SARS-CoV-2 binding to ACE2 causes a decrease in the ACE2 level and an increase in the ACE/ACE2 ratio due to an assumption that there was a competition between angiotensin II and SARS-CoV-2 for binding to ACE2. The occupation of ACE2 by the virus may lead a decrease conversion of angiotensin II to angiotensin 1-7 which has health promoting effects including vasculoprotective and antiinflammatory 
properties. Therefore, an enhancement in ACE/ACE2 may lead to an increase in inflammatory status due to elevated ACEdependent cytokine production and oxidative stress as well as decreased counteraction mediated by ACE2 products $(11,62)$. On the contrary, high expression of ACE2 in the heart and lung tissues of patients with comorbidities associated with severe COVID-19 was proposed to increase deleterious effect of virus infection by facilitating the SARSCoV-2 entry into cells $(63,64)$.

ACE inhibitors (ACEi) and angiotensin receptor blockers (ARB) enhance the expression of ACE2 (65). Therefore, increased ACE2 during treatment with these drugs are supposed both to produce favorable and unfavorable outcomes implying beneficial health effects versus facilitation of the virus entry. Although, there is still uncertainty about the associations of ACEi/ARB with COVID-19 disease susceptibility, however, a large population-based study showed that ACEi/ARB were associated with a reduced risk of COVID-19 disease without increasing intensive care unit admission (66). A multicenter retrospective study on hospitalized patients with COVID-19 reported that ACEi/ARB use was not associated with increased COVID-19 mortality (67). A meta-analysis study demonstrated no marked increase in the risk of COVID-19 infection in patients treating with $\mathrm{ACEi} / \mathrm{ARB}$, but a decrease in mortality (68). A comparison study among patients with COVID-19 showed that, continuation and discontinuation of ACEi/ARB have similar effects on acute hospitalisation outcomes. Therefore, it was recommended to continue the therapy with these medications in patients admitted to the hospital with COVID-19 (69). In this regard, ACEi/ARB therapy was found to attenuate the inflammatory response through the inhibition of interleukin-6 production in COVID-19 patients (70). However, an analysis study proposed that ACEi/ARBs-induced antiinflammatory effect may not be sufficient to produce a therapeutic impact in COVID-19 (71), thus explaining no significant difference in outcomes between patients with COVID-19 who are or not receiving these drugs (72). In COVID-19 patients, hyperinflammationrelated overproduction of proinflammatory factors, which is known a cytokine storm, can lead to multiorgan failure, development of acute respiratory distress syndrome and death (73-75). Although the use of corticosteroids, which are powerful antiinflammatory drugs, is still a controversial treatment of COVID-19, their use may be beneficial and safe in the hyperinflammatory phase of critically ill patients.
Supportingly, it has been reported that the early corticosteroid therapy in patients with moderate to severe COVID-19 attenuated progression to the hyperinflammation and improved clinical outcomes (76). Systemic high-dose corticosteroid therapy can be an effective way to increase the survival rates in COVID-19 patients with high inflammation levels (77).

\section{CONCLUSION}

ACE2, which is colocalized with TMPRSS2 and basigin, is a main receptor for SARS-CoV-2 binding to the epithelial cells in the airway and intestine as well as the endothelial cells of blood vessels, thus producing a critical step host cell entry of the virus. It can be concluded that there was a clear association between the localization of SARS-CoV-2 binding receptor ACE2 and the disease target organs in respiratory, cardiovascular and gastrointestinal systems. A decline in ACE2 receptor expression would prevent cellular entry of the virus thereby reducing progression of the infection. However, increased ACE2 expression could have beneficial effects in the maintenance of a healthy condition. More experimental and clinical studies are needed to clarify this conflicting situation. Currently, it is recommended to continue the therapy with ACE2-increasing drugs including ACE inhibitors and angiotensin receptor blockers in patients with COVID-19. Ongoing clinical trials will determine if the use of these drugs is favorable for the treatment of COVID-19.

\section{CONFLICT OF INTEREST}

No conflict of interest was declared by the authors.

\section{REFERENCES}

1. Chen N, Zhou M, Dong X, et al. Epidemiological and clinical characteristics of 99 cases of 2019 novel coronavirus pneumonia in Wuhan, China: a descriptive study. Lancet, 2020; 395(10223):507513. DOI: $10.1016 / \mathrm{S} 0140-6736(20) 30211-7$

2. Hopkins C, Surda P, Kumar N. Presentation of new onset anosmia during the COVID-19 pandemic. Rhinology, 2020; 58:295-298. DOI: 10.4193/Rhin20.116

3. Liu Y, Ning Z, Chen Y, et al. Aerodynamic analysis of SARS-CoV-2 in two Wuhan hospitals. Nature, 2020; 582(7813):557-560. DOI: $10.1038 / \mathrm{s} 41586$ 020-2271-3

4. Morawska L, Cao J. Airborne transmission of SARS-CoV-2: The world should face the reality. Environ Int, 2020; 139:105730. DOI: 10.1016/j.envint.2020.105730 
5. Li F. Structure, function, and evolution of coronavirus spike proteins. Annu Rev Virol, 2016; 3:237-61. DOI: 10.1146/annurev-virology-110615042301

6. Zhou P, Yang XL, Wang XG, et al. A pneumonia outbreak associated with a new coronavirus of probable bat origin. Nature, 2020; 579(7798):270273. DOI: $10.1038 / \mathrm{s} 41586-020-2012-7$

7. Li F, Li W, Farzan M, Harrison SC. Structure of SARS coronavirus spike receptor-binding domain complexed with receptor. Science, 2005; 309(5742):1864-1868.

10.1126/science. 1116480

8. Hoffmann M, Kleine-Weber H, Schroeder S, et al. SARS-CoV-2 cell entry depends on ACE2 and TMPRSS 2 and is blocked by a clinically proven protease inhibitor. Cell, 2020; 181(2):271-280. DOI: $10.1016 /$ j.cell.2020.02.052

9. Wrapp D, Wang N, Corbett KS, et al. Cryo-EM structure of the 2019-nCoV spike in the prefusion conformation. Science, 2020; 367(6483):12601263. DOI: $10.1126 /$ science.abb2507

10. Donoghue M, Hsieh F, Baronas E, et al. A novel angiotensin-converting enzyme-related carboxypeptidase (ACE2) converts angiotensin I to angiotensin 1-9. Circ Res, 2000; 87(5):1-9. DOI: 10.1161/01.res.87.5.e1

11. Paz Ocaranza M, Riquelme JA, García L, et al. Counter-regulatory renin-angiotensin system in cardiovascular disease. Nat Rev Cardiol, 2019; 17(2):116-129. DOI: 10.1038/s41569-019-0244-8

12. Bourgonje AR, Abdulle AE, Timens W, et al. Angiotensin-converting enzyme-2 (ACE2), SARSCoV-2 and pathophysiology of coronavirus disease 2019 (COVID-19). J Pathol, 2020; 251:228-248. DOI: $10.1002 /$ path.5471

13. Pagliaro P, Penna C. ACE/ACE2 Ratio: a key also in 2019 coronavirus disease (COVID-19)? Front Med, 2020; 7:335. DOI: 10.3389/fmed.2020.00335

14. Patel VB, Mori J, McLean BA, et al. ACE2 deficiency worsens epicardial adipose tissue inflammation and cardiac dysfunction in response to diet-induced obesity. Diabetes, 2016; 65(1):8595. DOI: $10.2337 / \mathrm{db} 15-0399$

15. Wang Y, Shoemaker R, Thatcher SE, BatifoulierYiannikouris F, English VL, Cassis LA. Administration of $17 \beta$-estradiol to ovariectomized obese female mice reverses obesity-hypertension through an ACE2-dependent mechanism. Am J Physiol Endocrinol Metab, 2015; 308(12):10661075. DOI: 10.1152/ajpendo.00030.2015

16. Li Y, Zhou W, Yang L, You R. Physiological and pathological regulation of ACE2, the SARS-CoV-2 receptor. Pharmacol Res, 2020; 157:104833. DOI: 10.1016/j.phrs.2020.104833

17. Xudong X, Junzhu C, Xingxiang W, Furong Z, Yanrong L. Age-and gender-related difference of ACE2 expression in rat lung. Life Sci, 2006; 78(19):2166-2171. DOI: 10.1016/j.lfs.2005.09.038

18. Bernardi S, Toffoli B, Zennaro C, et al. High-salt diet increases glomerular ACE/ACE2 ratio leading to oxidative stress and kidney damage. Nephrol
Dial Transplant, 2012; 27(5):1793-1800. DOI: 10.1093/ndt/gfr600

19. Giani JF, Muñoz MC, Mayer MA, et al. Angiotensin-(1-7) improves cardiac remodeling and inhibits growth-promoting pathways in the heart of fructose-fed rats. Am J Physiol Heart Circ Physiol, 2010; 298(3):1003-1013. DOI: 10.1152/ajpheart.00803.2009

20. Gupte M, Boustany-Kari CM, Bharadwaj K, et al. ACE2 is expressed in mouse adipocytes and regulated by a high-fat diet. Am J Physiol Regul Integr Comp Physiol, 2008; 295(3):781-788. DOI: 10.1152/ajpregu.00183.2008

21. Klimas J, Olvedy M, Ochodnicka-Mackovicova K, et al. Perinatally administered losartan augments renal ACE 2 expression but not cardiac or renal Mas receptor in spontaneously hypertensive rats. J Cell Mol Med, 2015; 19(8):1965-1974. DOI: 10.1111/jcmm. 12573

22. Ferrario CM, Jessup J, Chappell MC, et al. Effect of angiotensin-converting enzyme inhibition and angiotensin II receptor blockers on cardiac angiotensin-converting enzyme 2. Circulation, 2005; 111(20):2605-2610. DOI: 10.1161/CIRCULATIONAHA.104.510461

23. Vuille-dit-Bille RN, Camargo SM, Emmenegger L, et al. (2015). Human intestine luminal ACE2 and amino acid transporter expression increased by ACE-inhibitors. Amino Acids, 2015; 47(4):693705. DOI: $10.1007 / \mathrm{s} 00726-014-1889-6$

24. Hilliard LM, Sampson AK, Brown RD, Denton KM. The "his and hers" of the renin-angiotensin system. Curr Hypertens Rep, 2013; 15(1):71-79. DOI: $10.1007 / \mathrm{s} 11906-012-0319-\mathrm{y}$

25. Maric-Bilkan C, Manigrasso MB. Sex differences in hypertension: contribution of the reninangiotensin system. Gend Med, 2012; 9(4):287291. DOI: 10.1016/j.genm.2012.06.005

26. Kim EN, Kim MY, Lim JH, et al. The protective effect of resveratrol on vascular aging by modulation of the renin-angiotensin system. Atherosclerosis, 2018; 270:123-131. DOI: 10.1016/j.atherosclerosis.2018.01.043

27. Li W, Moore MJ, Vasilieva N, et al. Angiotensinconverting enzyme 2 is a functional receptor for the SARS coronavirus. Nature, 2003; 426(6965):450454. DOI: $10.1038 /$ nature02145

28. Batlle D, Wysocki J, Satchell K. (2020). Soluble angiotensin-converting enzyme 2: a potential approach for coronavirus infection therapy? Clin Sci (Lond), 2020; 134(5):543-545. DOI: 10.1042/CS20200163

29. Imai Y, Kuba K, Rao S, et al. Angiotensinconverting enzyme 2 protects from severe acute lung failure. Nature, 2005; 436(7047):112-116. DOI: $10.1038 /$ nature03712

30. Wösten-van Asperen RM, Lutter R, et al. Acute respiratory distress syndrome leads to reduced ratio of ACE/ACE2 activities and is prevented by angiotensin-(1-7) or an angiotensin II receptor antagonist. J Pathol, 2011; 225(4):618-627. DOI: 10.1002/path.2987 
31. Heurich A, Hofmann-Winkler H, Gierer S, Liepold T, Jahn O, Pöhlmann S. TMPRSS2 and ADAM17 cleave ACE2 differentially and only proteolysis by TMPRSS 2 augments entry driven by the severe acute respiratory syndrome coronavirus spike protein. J Virol, 2014; 88(2):1293-1307. DOI: 10.1128/JVI.02202-13

32. Xu J, Sriramula S, Xia H, et al. Clinical relevance and role of neuronal AT1 receptors in ADAM17mediated ACE2 shedding in neurogenic hypertension. Circ Res, 2017; 121(1):43-55. DOI: 10.1161/CIRCRESAHA.116.310509

33. Deshotels MR, Xia H, Sriramula S, Lazartigues E, Filipeanu CM. Angiotensin II mediates angiotensin converting enzyme type 2 internalization and degradation through an angiotensin II type I receptor-dependent mechanism. Hypertension, 2014; 64(6):1368-1375. DOI: 10.1161/HYPERTENSIONAHA.114.03743

34. Wang K, Chen W, Zhou YS, et al. SARS-CoV-2 invades host cells via a novel route: CD147-spike protein. BioRxiv, 2020. DOI: 10.1101/2020.03.14.988345

35. Ahmetaj-Shala B, Vaja RK, Atanur SS, George PM, Kirkby NS, Mitchell JA. Systemic analysis of putative SARS-CoV-2 entry and processing genes in cardiovascular tissues identifies a positive correlation of BSG with age in endothelial cells. BioRxiv, 2020. DOI: 10.1101/2020.06.23.165324

36. Chen Z, Mi L, Xu J, et al. Function of HAb18G/CD147 in invasion of host cells by severe acute respiratory syndrome coronavirus. J Infect Dis, 2005; 191(5):755-760. DOI: 10.1086/427811

37. Pennings GJ, Kritharides L. CD147 in cardiovascular disease and thrombosis. Semin Thromb Hemost, 2014; 40:747-755. DOI: 10.1055/s-0034-1390001

38. Suzuki K, Satoh K, Ikeda S, et al. Basigin promotes cardiac fibrosis and failure in response to chronic pressure overload in mice. Arterioscler Thromb Vasc Biol, 2016; 36(4):636-646. DOI: 10.1161/ATVBAHA.115.306686

39. Hamming I, Timens W, Bulthuis ML, Lely AT, Navis G, van Goor H. Tissue distribution of ACE2 protein, the functional receptor for SARS coronavirus. A first step in understanding SARS pathogenesis. J Pathol, 2004; 203(2):631-637. DOI: 10.1002/path. 1570

40. Srinivasan M, Zunt SL, Goldblatt LI. Oral epithelial expression of angiotensin converting enzyme-2: Implications for COVID-19 diagnosis and prognosis. BioRxiv, 2020. DOI: 10.1101/2020.06.22.165035

41. Qi F, Qian S, Zhang S, Zhang Z. Single cell RNA sequencing of 13 human tissues identify cell types and receptors of human coronaviruses. Biochem Biophys Res Commun, 2020; 526(1):135-140. DOI: 10.1016/j.bbrc.2020.03.044

42. Jia HP, Look DC, Shi L, et al. ACE2 receptor expression and severe acute respiratory syndrome coronavirus infection depend on differentiation of human airway epithelia. J Virol, 2005;
79(23):14614-14621.

DOI:

10.1128/JVI.79.23.14614-14621.2005

43. Ziegler CG, Allon SJ, Nyquist SK, et al. SARSCoV-2 receptor ACE2 is an interferon-stimulated gene in human airway epithelial cells and is detected in specific cell subsets across tissues. Cell, 2020; 181(5):1016-1035. DOI: 10.1016/j.cell.2020.04.035

44. Chen L, Liu M, Zhang Z, et al. Ocular manifestations of a hospitalised patient with confirmed 2019 novel coronavirus disease. $\mathrm{Br}$ J Ophthalmol, 2020; 104(6):748-751. DOI: 10.1136/bjophthalmol-2020-316304

45. Roehrich H, Yuan C, Hou JH. Immunohistochemical study of SARS-CoV-2 viral entry factors in the cornea and ocular surface. Cornea, 2020.2 DOI: 10.1097/ICO.0000000000002509

46. Zhou L, Xu Z, Castiglione GM, et al. ACE2 and TMPRSS2 are expressed on the human ocular surface, suggesting susceptibility to SARS-CoV-2 infection. Ocul Surf, 2020; 18(4):537-544. DOI: 10.1016/j.jtos.2020.06.007

47. Hashimoto T, Perlot T, Rehman A, et al. ACE2 links amino acid malnutrition to microbial ecology and intestinal inflammation. Nature, 2012; 487(7408):477-481. DOI: 10.1038/nature11228

48. Kowalczuk S, Bröer A, Tietze N, Vanslambrouck JM, Rasko JE, Bröer S. A protein complex in the brush-border membrane explains a Hartnup disorder allele. FASEB J, 2008; 22(8):2880-2887. DOI: $10.1096 / f j .08-107300$

49. D'Amico F, Baumgart DC, Danese S, PeyrinBiroulet L. Diarrhea during COVID-19 infection: pathogenesis, epidemiology, prevention and management. Clin Gastroenterol Hepatol, 2020; 18(8):1663-1672. DOI: 10.1016/j.cgh.2020.04.001

50. Lamers MM, Beumer J, van der Vaart J, et al. SARS-CoV-2 productively infects human gut enterocytes. Science, 2020; 369(6499):50-54. DOI: 10.1126/science.abc1669

51. Zhang H, Kang Z, Gong H, et al. Digestive system is a potential route of COVID-19: an analysis of single-cell coexpression pattern of key proteins in viral entry process. Gut, 2020; 69(6):1010-1018. DOI: 10.1136/gutjnl-2020-320953

52. Zang R, Castro MFG, McCune BT, et al. TMPRSS2 and TMPRSS4 promote SARS-CoV-2 infection of human small intestinal enterocytes. Sci Immunol, 2020; 5(47):eabc3582. DOI: 10.1126/sciimmunol.abc3582

53. Crackower MA, Sarao R, Oudit GY, et al. Angiotensin-converting enzyme 2 is an essential regulator of heart function. Nature, 2002; 17:822828. DOI: $10.1038 /$ nature00786

54. Sluimer JC, Gasc JM, Hamming I, et al. Angiotensin-converting enzyme 2 (ACE2) expression and activity in human carotid atherosclerotic lesions. J Pathol, 2008; 215(3):273279. DOI: $10.1002 /$ path. 2357

55. Escher R, Breakey N, Lämmle B. Severe COVID19 infection associated with endothelial activation. 
Thromb Res, 2020; 190:62. DOI: 10.1016/j.thromres.2020.04.014

56. Zhang Y, Xiao M, Zhang S, Xia P, Caio W, Jiang W. Coagulopathy and antiphospholipid antibodies in patients with COVID-19. N Engl J Med, 2020; 382(17):e38. DOI: 10.1056/NEJMc2007575

57. Varga Z, Flammer AJ, Steiger P, et al. Endothelial cell infection and endotheliitis in COVID-19. Lancet, 2020; 395(10234):1417-1418. DOI: 10.1016/S0140-6736(20)30937-5

58. Guan WJ, Ni ZY, $\mathrm{Hu} \mathrm{Y}$, et al. Clinical characteristics of coronavirus disease 2019 in China. N Engl J Med, 2020; 382(18):1708-1720. DOI: $10.1056 /$ NEJMoa2002032

59. Tikellis C, Thomas MC. Angiotensin-converting enzyme 2 (ACE2) is a key modulator of the renin angiotensin system in health and disease. Int J Pept, 2012; 2012:256294. DOI: 10.1155/2012/256294

60. Cheng H, Wang Y, Wang GQ. Organ-protective effect of angiotensin-converting enzyme 2 and its effect on the prognosis of COVID-19. J Med Virol, 2020; 92(7):726-730. DOI: 10.1002/jmv.25785

61. Liu Y, Yang Y, Zhang C, et al. Clinical and biochemical indexes from 2019-nCoV infected patients linked to viral loads and lung injury. Sci China Life Sci, 2020; 63(3):364-374. DOI: 10.1007/s11427-020-1643-8

62. Rincón J, Correia D, Arcaya JL, et al. Role of Angiotensin II type 1 receptor on renal NAD(P)H oxidase, oxidative stress and inflammation in nitric oxide inhibition induced-hypertension. Life Sci, 2015; 124:81-90. DOI: 10.1016/j.lfs.2015.01.005.

63. Chen L, Li X, Chen M, Feng Y, Xiong C. The ACE2 expression in human heart indicates new potential mechanism of heart injury among patients infected with SARS-CoV-2. Cardiovasc Res, 2020; 116(6):1097-1100. DOI: 10.1093/cvr/cvaa078.

64. Pinto BGG, Oliveira AER, Singh Y, et al. ACE2 expression is increased in the lungs of patients with comorbidities associated with severe COVID-19. J Infect Dis, 2020; 222(4):556-563. DOI: 10.1093/infdis/jiaa332.

65. Arendse LB, Danser AHJ, Poglitsch M, et al. Novel therapeutic approaches targeting the reninangiotensin system and associated peptides in hypertension and heart failure. Pharmacol Rev, 2019; 71(4):539-570. DOI: 10.1124/pr.118.017129.

66. Hippisley-Cox J, Young D, Coupland C, et al. Risk of severe COVID-19 disease with ACE inhibitors and angiotensin receptor blockers: cohort study including 8.3 million people. Heart, 2020; 106(19):1503-1511. DOI: 10.1136/heartjnl-2020317393.

67. Zhang P, Zhu L, Cai J, et al. Association of inpatient use of angiotensin-converting enzyme inhibitors and angiotensin ii receptor blockers with mortality among patients with hypertension hospitalized with COVID-19. Circ Res, 2020; 126(12):1671-1681. DOI: 10.1161/CIRCRESAHA.120.317134.

68. Liu X, Long C, Xiong Q, et al. Association of angiotensin converting enzyme inhibitors and angiotensin II receptor blockers with risk of COVID-19, inflammation level, severity, and death in patients with COVID-19: A rapid systematic review and meta-analysis. Clin Cardiol, 2020; 10.1002/clc.23421. DOI: 10.1002/clc.23421.

69. Cohen JB, Hanff TC, William P, et al. Continuation versus discontinuation of renin-angiotensin system inhibitors in patients admitted to hospital with COVID-19: a prospective, randomised, open-label trial. Lancet Respir Med, 2021. DOI: 10.1016/S2213-2600(20)30558-0.

70. Meng J, Xiao G, Zhang J, et al. Renin-angiotensin system inhibitors improve the clinical outcomes of COVID-19 patients with hypertension. Emerg Microbes Infect, 2020; 9(1):757-760. DOI: 10.1080/22221751.2020.1746200.

71. Hallow KM, Dave I. RAAS blockade and COVID19: Mechanistic modeling of mas and at 1 receptor occupancy as indicators of pro- and antiinflammatory balance. Clin Pharmacol Ther, 2021. DOI: $10.1002 /$ cpt.2177.

72. Flacco ME, Acuti Martellucci C, Bravi F, et al. Treatment with ACE inhibitors or ARBs and risk of severe/lethal COVID-19: a meta-analysis. Heart, 2020; 106(19):1519-1524. DOI: 10.1136/heartjnl2020-317336.

73. Mehta P, McAuley DF, Brown M, Sanchez E, Tattersall RS, Manson JJ. COVID-19: consider cytokine storm syndromes and immunosuppression. Lancet, 2020; 395(10229):1033-1034. DOI: 10.1016/S01406736(20)30628-0.

74. Coperchini F, Chiovato L, Croce L, Magri F, Rotondi M. The cytokine storm in COVID-19: An overview of the involvement of the chemokine/chemokine-receptor system. Cytokine Growth Factor Rev, 2020; 53:25-32. DOI: 10.1016/j.cytogfr.2020.05.003.

75. Gilzad-Kohan H, Jamali F. Anti-inflammatory properties of drugs used to control covid-19 and their effects on the renin-angiotensin system and angiotensin-converting Enzyme-2. J Pharm Pharm Sci, 2020; 23:259-277. DOI: 10.18433/jpps31346.

76. Fadel R, Morrison AR, Vahia A, et al. Early shortcourse corticosteroids in hospitalized patients with COVID-19. Clin Infect Dis, 2020; 71(16):21142120. DOI: $10.1093 / \mathrm{cid} / \mathrm{ciaa} 601$.

77. López Zúñiga MÁ, Moreno-Moral A, OcañaGranados A, et al. High-dose corticosteroid pulse therapy increases the survival rate in COVID-19 patients at risk of hyper-inflammatory response. PLoS One, 2021; 16(1):e0243964. DOI: 10.1371/journal.pone.0243964. 